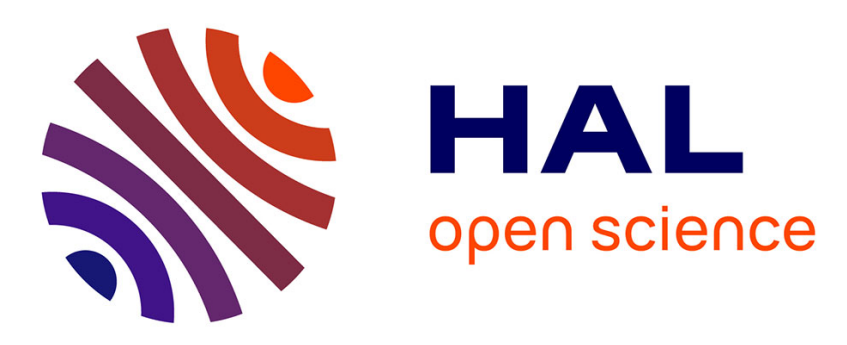

\title{
Variability of venom components in immune suppressive parasitoid wasps: From a phylogenetic to a population approach
}

Dominique Colinet, Hugo Mathe-Hubert, Roland Allemand, Jean-Luc Gatti, Marylène Poirié

\section{To cite this version:}

Dominique Colinet, Hugo Mathe-Hubert, Roland Allemand, Jean-Luc Gatti, Marylène Poirié. Variability of venom components in immune suppressive parasitoid wasps: From a phylogenetic to a population approach. Journal of Insect Physiology, 2013, 59 (2), pp.205-212. 10.1016/j.jinsphys.2012.10.013 . hal-02168304

\section{HAL Id: hal-02168304 https://hal.science/hal-02168304}

Submitted on 28 Jun 2019

HAL is a multi-disciplinary open access archive for the deposit and dissemination of scientific research documents, whether they are published or not. The documents may come from teaching and research institutions in France or abroad, or from public or private research centers.
L'archive ouverte pluridisciplinaire HAL, est destinée au dépôt et à la diffusion de documents scientifiques de niveau recherche, publiés ou non, émanant des établissements d'enseignement et de recherche français ou étrangers, des laboratoires publics ou privés. 
archives-ouvertes

\section{Variability of venom components in immune suppressive parasitoid wasps: From a phylogenetic to a population approach}

Dominique Colinet, Hugo Mathe-Hubert, Roland Allemand, Jean-Luc Gatti, Marylène Poirie

\section{To cite this version:}

Dominique Colinet, Hugo Mathe-Hubert, Roland Allemand, Jean-Luc Gatti, Marylène Poirie. Variability of venom components in immune suppressive parasitoid wasps: From a phylogenetic to a population approach. Journal of Insect Physiology, Elsevier, 2013, 59 (2), pp.205-212. 10.1016/j.jinsphys.2012.10.013 . hal-02168304

\section{HAL Id: hal-02168304 \\ https://hal.archives-ouvertes.fr/hal-02168304}

Submitted on 28 Jun 2019

HAL is a multi-disciplinary open access archive for the deposit and dissemination of scientific research documents, whether they are published or not. The documents may come from teaching and research institutions in France or abroad, or from public or private research centers.
L'archive ouverte pluridisciplinaire HAL, est destinée au dépôt et à la diffusion de documents scientifiques de niveau recherche, publiés ou non, émanant des établissements d'enseignement et de recherche français ou étrangers, des laboratoires publics ou privés. 


\title{
Variability of venom components in immune suppressive parasitoid wasps: From a phylogenetic to a population approach
}

\author{
Dominique Colinet $^{\text {a,b,c }}$, Hugo Mathé-Hubert ${ }^{\mathrm{a}, \mathrm{b}, \mathrm{c}}$, Roland Allemand ${ }^{\mathrm{d}}$, Jean-Luc Gatti ${ }^{\mathrm{a}, \mathrm{b}, \mathrm{c}}$, \\ Marylène Poirié $\mathrm{a,b,c,*}$ \\ ${ }^{a}$ Institut National de la Recherche Agronomique (INRA), Evolution and Specificity of Multitrophic Interactions (ESIM), UMR 1355 Institut Sophia Agrobiotech (ISA), Sophia \\ Antipolis, France \\ ${ }^{\mathrm{b}}$ Centre National de la Recherche Scientifique (CNRS), UMR 7254, Sophia Antipolis, France \\ ${ }^{\mathrm{c}}$ Université Nice Sophia Antipolis, UFR Sciences, Sophia Antipolis, France \\ dUniversité de Lyon, F-69000, Lyon; Université Lyon 1; CNRS, UMR 5558, Laboratoire de Biométrie et Biologie Evolutive, F-69622, Villeurbanne, France
}

Keywords:

Parasitoid wasps

Venom proteins

Immune suppression

Intraspecific variability

Individual electrophoretic profiles

Leptopilina

Psyttalia

Drosophila

\begin{abstract}
:
Endoparasitoid wasps develop at the expense of other insects, leading to their death. Eggs deposited inside the host body induce an immune response, which results in the formation of a melanized cellular capsule around the egg. To evade or counteract this response, endoparasitoids have evolved different strategies, the most often reported being injection into the host of immunosuppressive factors, notably venom proteins, along with the egg. The analysis of venom components has been performed independently in species of different taxa, but the present picture is far from complete. Intriguingly, the question of the level of venom variability inside species has been neglected, although it may partly determine the potential for parasitoid adaptation. Here, we present a short review of our present knowledge of venom components in endoparasitoids, asell as of the only well-known example of intraspecific variability in a venom immune suppressive protein being responsible for variation in parasitoid virulence. We then present data evidencing inter-individual variation of venom protein profiles, using a gel electrophoresis approach, both in laboratory strains and field populations of a figitid and a braconid species. Whether occurrence of such variability may permit a selection of parasitoid venom components driven by the host remains to be tested, notably in the context of the production and use of biological control auxiliaries.
\end{abstract}

\section{Introduction}

Within parasites, insect parasitoids are remarkable by the diversity and originality of their virulence strategies. They lay eggs on or inside the body of other insects (mainly egg, larval or pupal stages) and achieve their development by consuming the host tissues, leading to its death (Godfray, 1994; Quicke, 1997). The parasitoid lifestyle is predominantly found in two insect orders: more than 60,000 species belong to Hymenoptera, others being mainly Diptera. Parasitoids are also classified into idiobionts which generally paralyze their host immediately following parasitism, stopping them from further development, and koinobionts which allow the host to continue feeding and developing. Ectoparasitoids feed externally on the host in contrast to endoparasitoids that develop inside the host (Godfray, 1994; Quicke, 1997). There is a large body of literature on parasitoid life-history traits such as host choice

\footnotetext{
* Corresponding author. Address: Evolution and Specificity of Multitrophic Interactions (ESIM), UMR 1355 "Sophia Agrobiotech Institute" (ISA), Institut National de la Recherche Agronomique, INRA PACA, 400 route des Chappes, Sophia Antipolis 06903, France. Tel.: +33 492386409.

E-mail address: poirie@sophia.inra.fr (M. Poirié).
}

behavior, foraging strategies, population dynamics, or resources allocation (Jervis et al., 2008; Lohse et al., 2012; Wajnberg et al., 2012). As parasitoids develop an obligate and intimate relationship with their hosts, and often exert a strong selection pressure on their populations, focus has also been made on co-evolutionary aspects, notably for immune traits (e.g. geographic variation in parasitoid virulence and host resistance) (Dupas et al., 2009; Kraaijeveld and van Alphen, 1994). Selection of specific adaptations in response to host defenses may partly explain the specialization of many parasitoids to one host or a narrow range of hosts, a trait that makes them valuable tools for biological control of vectors and pests.

Comparative studies of host-endoparasitoid interactions, mainly performed for dipteran and lepidopteran hosts, have provided insights on insect immune processes. The insect response to the intrusion of a foreign object too large to be phagocytized, such as a parasitoid egg, is the encapsulation process, which requires both cellular and humoral components (Carton et al., 2008). Specialized hemocytes adhere to the egg and surround it with organized successive layers, while activation of the phenoloxidase cascade leads to melanization of the capsule and the production of cytotoxic radicals that ends in the parasitoid 
death (Fauvarque and Williams, 2011; Nappi, 2010; Nappi et al., 2009; Strand, 2008). To evade or counteract the host immune reaction, endoparasitoids have evolved different strategies (Poirié et al., 2009), the more often described being active immunosuppression that can be local or systemic. It generally involves alteration or destruction of immune cells whether circulating or present in the hematopoietic organ, and/or inhibition of the melanization process by targeting of the phenoloxidase (PO) cascade, notably the serine proteases involved in the pro-phenoloxidase (proPO) activation into active PO (Poirié et al., 2009). Interestingly, ectoparasitoid females can inject factors that alter host immune components, as do endoparasitoid females (Danneels et al., 2010).

Important modifications of the stinging apparatus and the secretions it delivers have occurred in the evolution of Hymenoptera, as strong adaptations to their lifestyle (e.g. prey capture, defense against enemies). In addition to the egg and ovarian fluids, parasitoid females inject secretions produced in specialized glands derived from the reproductive tissue (notably venom glands) that will ensure host immune suppression. Female-injected components are thus a complex mixture of ovarian and venom proteins, that can also include peptides, vesicular or virus-like components (equally described as Virus-Like Particles, VLPs) produced in the ovarian calyx or the venom gland, and viruses (such as polydnaviruses, PDVs) (Asgari and Rivers, 2010; Beckage, 2012; Gatti et al., 2012; Poirié et al., 2009; Strand, 2012). Polydnaviruses, being considered as a unique example of a symbiotic association between a virus and an eukaryotic organism, have been paid a lot of attention (for recent reviews see Beckage, 2012; Burke and Strand, 2012; Strand, 2012) and will not be further discussed here.

Venom peptides and small proteins have been scarcely studied in parasitoids although analyses of venom gland transcriptomes suggest they are indeed present in the venom (Hauser et al., 2010). For instance, a venom defensin-like peptide of 56 aa has been characterized in Nasonia vitripennis that may interfere with the host phenoloxidase cascade (Tian et al., 2010). Interestingly, a venom peptide from Cotesia rubecula (Vn1.5) was also found to be required for expression of its PDV-associated genes in Pieris rapae host cells (Zhang et al., 2004a).

The VLPs observed in the venom of a large range of phylogenetically distant parasitoid wasps (Dupas et al., 1996; Morales et al., 2005; review in Gatti et al., 2012) are diverse in form and size among species but also heterogeneous within species. The observed particles more or less resemble viruses, but they are apparently devoid of DNA or RNA, and the few VLPs-associated proteins characterized to date have no similarity with viral proteins (Gatti et al., 2012). VLPs were first purified following separation on density gradients of the venom reservoir content of the figitid Leptopilina heterotoma (Rizki and Rizki, 1990), and shown to be involved in suppression of the Drosophila melanogaster host immunity. Although they were demonstrated to enter lamellocytes (the main capsule-forming hemocytes) and to induce changes in their morphology (Rizki and Rizki, 1984, 1990, 1994), their mechanism of entry and mode of action have not been described, and none of the reported VLP proteins have yet been clearly identified nor their function described (Chiu et al., 2006; Gatti et al., 2012). A role of venom VLPs of the phylogenetically distant braconid Meteorus pulchricornis in modifying hemocyte properties was also demonstrated in the host Pseudaletia separata (Suzuki et al., 2008).

The analysis of components injected by parasitoid females is far from being complete. Besides, the factors present in different fluids (ovarian fluid, venom) can have antagonistic or agonistic effects on the host physiology (Mabiala-Moundoungou et al., 2010; Zhang et al., 2004a). In this paper, we will mainly focus on venom components in endoparasitoids, and the different levels at which variability may be observed.

\section{Analysis of venom components: from venom markers to virulence factors?}

A main problem in studying venom composition is to obtain venom free of cellular proteins. Parasitoid venom apparatus are diverse (Edson and Vinson, 1979; Vardal, 2006): for instance, venom glands can appear as a long filament with only a small canal filled with venom (e.g. in Leptopilina figitid species), or as large multi-lobed glands containing a substantial quantity of secreted fluid (e.g. in Psyttalia braconid wasps). The shape and histological structure of reservoirs also varies from a thick muscular layer enclosing a small amount of venom (Edson et al., 1982), which likely serve as a pump (in most braconid wasps), to a large cylinder with a thin cellular wall, containing up to several nanoliters of venom (for example in Leptopilina wasps). As collection of venom without damaging tissues can be difficult depending on species, typical cellular proteins may be found among venom proteins (Vincent et al., 2010), and whether they are indeed secreted or correspond to contaminants can prove hard to determine.

Different levels of analysis can be performed on collected "pure" venom, from a simple observation and comparison of protein profiles to a proteomic approach aimed at identifying proteins and assign them putative functions. The use of targeted approaches, such as extensive characterization of a given protein band, has proved successful in the past (Asgari, 2012; Asgari and Rivers, 2010; Poirié et al., 2009). However, it requires an accurate choice of the protein to focus on, and, until now, the number of proteins characterized from parasitoid venom fluids with this approach is rather limited. Enzymatic functions can often be easily identified by gel zymography (e.g. for superoxide dismutase activity; Colinet et al., 2011), or by enzymatic assays with crude venom (e.g. for hyaluronidase; Nakamatsu and Tanaka, 2004 or acid phosphatase activity; Zhu et al., 2008). Further identification of the involvement of a given protein in suppressing host immunity for instance (e.g. inhibition of the phenoloxidase cascade, alteration of hemocyte adhesion or morphology) requires further in vivo and in vitro analyses using the purified or a recombinant protein. At the moment, final demonstration of the major role of a protein as a virulence factor has been performed by microinjecting the protein in vivo in presence of a specific antibody (Colinet et al., 2010), other methods such as RNAi being unfortunately not available yet for endoparasitoids.

Parasitoid studies have also focused on the question of the venom protein diversity in more or less related species. Global approaches based on comparisons of protein electrophoretic profiles do not easily allow concluding on the common origin or function of a given protein in absence of accurate molecular identification, such identification being difficult when the protein does not match any sequence in databases. Meanwhile, gel electrophoresis is a routinely used method, and we thus questioned whether more information could be obtained from protein profiles. With the interest in discovering markers from protein samples in human pathologies as cancer, new digital imaging technologies have been developed that allows analyzing such profiles both qualitatively and quantitatively from dozens of samples (Hanash and Taguchi, 2010; Wulfkuhle et al., 2003). Using this approach, venom variability can be estimated not only between closely-related species or populations (i.e. pooled samples), but also between individuals of a given population, a parameter that has not been investigated in depth until now. This question is of high interest since the occurrence of such variability is a pre-requisite for selection on parasitoid venom, which may drive parasitoid adaptation in response to parameters such as host species or host resistance. Moreover, the capacity of venom to rapidly evolve may explain the diversity of venom contents between species, the presence or abundance of specific proteins 
resulting from short-term adaptive processes rather than a common evolutionary origin. The differences between protein profiles may also focus our attention to proteins of interest possibly involved in adaptive processes, and acting as virulence factors.

\section{Venom components function and diversity: available data}

\subsection{Virulence factors in different species}

Global comparisons of venom electrophoretic profiles of parasitoid and non-parasitoid (bees, aculeate wasps, ants) hymenopteran species have been performed. The largest study included 25 hymenopteran species from 21 genera, with 4 braconid and 2 unknown ichneumonid parasitic wasps (Leluk et al., 1989). It showed that parasitoid wasp venom contain proteins ranging from $20 \mathrm{kDa}$ to several hundred $\mathrm{kDa}$, some of them being glycosylated, but with no major protein bands in the "peptide" range $(<15 \mathrm{kDa})$. The protein patterns strongly differed from one species to another, even between the closely related braconids, Chelonus insularis and $C$. near curvimaculatus. Interestingly, a large number of $C$. insularis, but also of ants venom proteins, were recognized by an antiserum raised against $C$. near curvimaculatus venom, while fewer proteins were detected in aculeate wasp and bee venoms. This confirms that accurate comparison of venom between species cannot simply rely on visual comparisons of protein profiles.

Over the last few years, the development of DNA sequencing and mass spectrometry technologies has allowed a booming increase of venom protein characterization (Asgari and Rivers, 2010; Formesyn et al., 2012). The first large-scale analyses combining transcriptome and partial proteome analyses to identify putative venom proteins were performed in the ichneumonid Pimpla hypochondriaca (Parkinson et al., 2003, 2004) and two braconid Microctonus species (Crawford et al., 2008). More recently, a number of venom proteins were identified from the chalcidoids Pteromalus puparum (Zhu et al., 2010b) and N. vitripennis (de Graaf et al., 2010), using a proteomic approach. For $N$. vitripennis, whose genome sequence is available, the proteomic analysis was combined with bioinformatics, leading to identification of as much as 79 putative venom constituents (de Graaf et al., 2010). Finally, a total of 29 venom proteins were recently identified from the endoparasitoid Chelonus inanitus using a combined transcriptomic and proteomic approach aimed at discriminating between cellular and true venom proteins (Vincent et al., 2010). However, many of the identified proteins in these and other studies did not show any similarity with known proteins, a recurrent problem in parasitoid venom analyses. This is certainly due to the absence of complete annotated genomes of parasitoids species (except those of Nasonia spp.), a severe drawback for a complete identification and comparison of proteins.

With more than 50 venom proteins identified in different species, a better picture of the complex nature and diversity of venom components has recently been acquired. However, only $<20 \%$ of them have been demonstrated to alter host physiology (Table 1). Three venom proteins that inhibit the host cellular immune response have been described so far (Table 1 ). In L. boulardi, a RhoGAP domain-containing protein, LbGAP, targets Drosophila lamellocytes, and induces changes in their morphology rendering them unable to perform encapsulation (Labrosse et al., 2005). LbGAP has been demonstrated to inactivate two Drosophila Rho GTPases, Rac1 and Rac2 (Colinet et al., 2007), both involved in cytoskeletal rearrangements and adhesions necessary for cell-shape change and migration and proved to be necessary for parasitism success. A calreticulin from $C$. rubecula has been shown to prevent encapsulation in vitro by inhibiting hemocyte spreading behavior, although the mechanism is still unclear (Zhang et al., 2006). This protein is also present in the venom of $N$. vitripennis (de Graaf et al., 2010) and P. puparum (Zhu et al., 2010b). Finally, a P. hypochondriaca venom protein, without any similarity to known proteins, also shows insect hemocyte anti-aggregation properties thus inhibiting encapsulation (Richards and Dani, 2008). Some venom proteins were demonstrated to inhibit the humoral component of the anti-parasitoid response, by interfering with the PO cascade (Table 1). Vn50, a serine protease homolog devoid of activity is secreted in C. rubecula venom. It acts as an inhibitor of $P$. rapae host hemolymph melanization, presumably by competing with host serine protease homologs for binding to proPO, while remaining non cleaved and stable in the hemolymph (Asgari et al., 2003a; Zhang et al., 2004b). Interestingly, members of the serine protease family have also been found in the venom of four other parasitoids (Table 1). C. rubecula venom also contains a small protein (Vn4.6), with similarities to atracotoxins but also to cystein-rich protease inhibitors, that inhibits melanization through an unknown mechanism (Asgari et al., 2003b). In L. boulardi, a venom protein from the serine protease inhibitor (serpin) family, LbSPNy, was demonstrated to prevent melanization in Drosophila through inhibition of PO activation (Colinet et al., 2009). Interestingly, L. boulardi venom also contains an extracellular SOD that in vitro inhibits the host phenoloxidase activity and might interfere locally with the melanization process (Colinet et al., 2011). In addition to venom proteins regulating host immunity, a gamma glutamyl transpeptidase from Aphidius ervi was shown to target host reproduction by inducing apoptosis in aphid ovaries (Falabella et al., 2007), a reprolysin-type metalloprotease from Eulophus pennicornis manipulates host development and display toxicity towards the host (Price et al., 2009), and pimplin, a small polypeptide from P. hypochondriaca, with no similarities with any known protein, induces paralysis of the host (Parkinson et al., 2002c) (Table 1).

Comparisons of identified proteins between Hymenoptera suggest that some venom components are largely shared (e.g. acid phosphatases, venom-allergen proteins related to cystein-rich secretory proteins, metalloproteases, serine proteases) and may have an ancestral origin, while others are specific to one or a few parasitoid species (Table 1). Interestingly, the shared proteins, or family-related proteins, are also retrieved in the venom of a large number of organisms such as snakes, scorpions or centripedes, as well as in secretions from salivary glands and different exocrine organs, in species ranging from insects to mammals (Pilch and Mann, 2006; Zhou et al., 2007; Chapman, 2008; Fry et al., 2009; Belleannée et al., 2010). This set of proteins, which has likely been selected for its role in predation or defense, might also be important for protection/maturation of secreted proteins or involved in the process of secretion.

Venom proteins have rarely been globally analyzed in closely related parasitoid species. The only work carried out on two Microctonus parasitoid species only focused on variation of the expression level of a small number of genes in the venom apparatus (Crawford et al., 2008). An interesting model would be Leptopilina species whose interactions with Drosophila hosts have longbeen studied (Jenni, 1951; Nappi, 1977; Rizki et al., 1990), L. boulardi being also the species whose venom virulence factors are among the best characterized. To our knowledge, the main immune suppressive factor, LbGAP, is also the only factor demonstrated to be required for parasitoid virulence (Colinet et al., 2010). Studies on other Leptopilina species are still far from this point but venom analyses are currently performed. $L$. boulardi and $L$. heterotoma differ by the host range (Fleury et al., 2009), venom effects on the Drosophila host (Lee et al., 2009), and changes in expression profiles of host genes following parasitism (Lee et al., 2011; Schlenke et al., 2007). Interestingly, we observed major differences in venom protein profiles of the two species (Fig. 1). Accordingly, we also evidenced a quantitative difference in expres- 
Table 1

Venom proteins identified from parasitic wasps, having known or putative biochemical functions. Ae, Aphidius ervi; At, Asobara tabida; Cc, Chelonus sp. near curvimaculatus; Ci, Chelonus inanitus; Cr, Cotesia rubecula; Ep, Eulophus pennicornis; Ma, Microctonus aethiopoides; Mh, Microctonus hyperodae; Nv, Nasonia vitripennis; Ph, Pimpla hypochondriaca; Pp, Pteromalus puparum; Pt, Pimpla turionellae. Only proteins with a demonstrated effect on the host physiology are discussed in the manuscript.

\begin{tabular}{|c|c|c|c|}
\hline & Demonstrated effect on host physiology & Species & References \\
\hline \multicolumn{4}{|l|}{ Enzymes } \\
\hline Alpha- $N$-acetyl glucosaminidase & & $\mathrm{Ci}$ & Vincent et al. (2010) \\
\hline Alkaline phosphatase & & $\mathrm{Pp}$ & Zhu et al. (2010a) \\
\hline Aminotransferase-like venom protein & & Nv, Pp & de Graaf et al. (2010) and Zhu et al. (2010b) \\
\hline Angiotensin-converting enzyme & & $\mathrm{Ci}$ & Vincent et al. (2010) \\
\hline Apyrase & & $\mathrm{Nv}$ & de Graaf et al. (2010) \\
\hline Arginine kinase & & $\mathrm{Pp}$ & Zhu et al. (2010b) \\
\hline Arylsulfatase & & Nv & de Graaf et al. (2010) \\
\hline Aspartylglucosaminidase & & At & Moreau et al. (2004) \\
\hline ATP synthase & & $\mathrm{Pp}$ & Zhu et al. (2010b) \\
\hline C1A protease & & $\mathrm{Ci}$ & Vincent et al. (2010) \\
\hline Chitinase & & $\mathrm{Cc}, \mathrm{Ci}$ & Krishnan et al. (1994) and Vincent et al. (2010) \\
\hline Dipeptidylpeptidase IV & & $\mathrm{Nv}$ & de Graaf et al. (2010) \\
\hline Endonuclease-like venom protein & & Nv & de Graaf et al. (2010) \\
\hline Esterase/lipase & & $\mathrm{Ci}$ & Vincent et al. (2010) \\
\hline Gamma glutamyl transpeptidase & Induction of apoptosis in host ovaries (Ae) & Ae, Nv & Falabella et al. (2007) and de Graaf et al. (2010) \\
\hline $\begin{array}{l}\text { Glucose-Methanol-Choline (GMC) } \\
\text { oxidoreductase }\end{array}$ & & Nv & de Graaf et al. (2010) \\
\hline $\begin{array}{l}\text { Inosine-uridine preferring nucleoside } \\
\text { hydrolase }\end{array}$ & & $\mathrm{Nv}, \mathrm{Pp}$ & de Graaf et al. (2010) and Zhu et al. (2010b) \\
\hline Laccase & & $\mathrm{Ph}$ & Parkinson et al. (2003) \\
\hline Metalloprotease & $\begin{array}{l}\text { Toxicity towards the host, manipulation of } \\
\text { host development (Ep) }\end{array}$ & $\mathrm{Ci}, \mathrm{Ep}, \mathrm{Ph}$ & $\begin{array}{l}\text { Vincent et al. (2010), Price et al. (2009) and Parkinson et al. } \\
\text { (2002a) }\end{array}$ \\
\hline $\begin{array}{l}\text { Multiple inositol polyphosphate } \\
\text { phosphatase-like venom protein }\end{array}$ & & $\mathrm{Nv}$ & de Graaf et al. (2010) \\
\hline Neprilysin & & $\mathrm{Mh}$ & Crawford et al. (2008) \\
\hline Phenoloxidase & & $\mathrm{Ph}$ & Parkinson et al. (2001) \\
\hline Phospholipase B & & $\mathrm{Pt}$ & Uçkan et al. (2006) \\
\hline $\begin{array}{l}\text { Serine proteases and serine protease } \\
\text { homologs }\end{array}$ & Inhibition of melanization $(\mathrm{Cr})$ & $\begin{array}{l}\mathrm{Ci}, \mathrm{Cr}, \mathrm{Nv} \\
\mathrm{Ph}, \mathrm{Pp}\end{array}$ & $\begin{array}{l}\text { Vincent et al. (2010), Asgari et al. (2003a), de Graaf et al. (2010), } \\
\text { Parkinson et al. (2002b) and Zhu et al. (2010b) }\end{array}$ \\
\hline Superoxide dismutase & $\begin{array}{l}\text { In vitro inhibition of Drosophila } \\
\text { phenoloxidase activity }\end{array}$ & $\mathrm{Lb}$ & Colinet et al. (2011) \\
\hline Trehalase & & $\mathrm{Ph}$ & Parkinson et al. (2003) \\
\hline Venom acid phosphatase & & $\begin{array}{l}\text { Nv, Ph, } \\
\mathrm{Pp}\end{array}$ & de Graaf et al. (2010), Dani et al. (2005) and Zhu et al. (2008) \\
\hline \multicolumn{4}{|l|}{ Recognition/binding proteins } \\
\hline Beta-1,3-glucan recognition protein & & Nv & de Graaf et al. (2010) \\
\hline Chitin binding protein & & $\mathrm{Ci}, \mathrm{Nv}$ & Vincent et al. (2010), de Graaf et al. (2010) \\
\hline Lectin & & $\mathrm{Ci}$ & Vincent et al. (2010) \\
\hline Low-density lipoprotein receptor & & $\mathrm{Nv}$ & de Graaf et al. (2010) \\
\hline \multicolumn{4}{|l|}{ Protease inhibitors } \\
\hline Cysteine-rich protease inhibitor & & $\mathrm{Nv}, \mathrm{Ph}$ & de Graaf et al. (2010) and Parkinson et al. (2004) \\
\hline Kazal-type serine protease inhibitor & & Nv & de Graaf et al. (2010) \\
\hline Serpin & Inhibition of melanization & $\mathrm{Lb}$ & Colinet et al. (2009) \\
\hline \multicolumn{4}{|l|}{ Chaperone } \\
\hline Calreticulin & $\begin{array}{l}\text { Inhibition of hemocyte spreading behavior, } \\
\text { suppression of encapsulation }(\mathrm{Cr})\end{array}$ & $\mathrm{Cr}, \mathrm{Nv}, \mathrm{Pp}$ & Zhang et al. (2006), de Graaf et al. (2010) and Zhu et al. (2010b) \\
\hline Heat shock protein & & $\mathrm{Pp}$ & Zhu et al. (2010b) \\
\hline \multicolumn{4}{|l|}{ Cytoskeleton components } \\
\hline Actin & & $\mathrm{Pp}$ & Zhu et al. (2010b) \\
\hline Tropomyosin & & $\mathrm{Pp}$ & \\
\hline \multicolumn{4}{|l|}{ Neurotoxin-like/Paralytic factors } \\
\hline Fire Ant venom allergen III & & Ma, Mh & Crawford et al. (2008) \\
\hline Pimplin & Paralysis of the host & $\mathrm{Ph}$ & Parkinson et al. (2002c) \\
\hline Vn4.6 (similar to atracotoxins) & Inhibition of melanization & $\mathrm{Cr}$ & Asgari et al. (2003b) \\
\hline \multicolumn{4}{|l|}{ Others } \\
\hline Antigen 5-like protein & & $\mathrm{Nv}$ & de Graaf et al. (2010) \\
\hline Chemosensory protein-like protein & & $\mathrm{Ci}$ & Vincent et al. (2010) \\
\hline General odorant binding protein & & $\mathrm{Ci}, \mathrm{Nv}$ & Vincent et al. (2010) and de Graaf et al. (2010) \\
\hline Hexamerin & & $\mathrm{Pp}$ & Zhu et al. (2010b) \\
\hline Imaginal disc Growth Factors-like & & $\mathrm{Ci}$ & Vincent et al. (2010) \\
\hline Immunoglobulin-like venom protein & & $\mathrm{Nv}$ & de Graaf et al. (2010) \\
\hline $\begin{array}{l}\text { Insect hemocyte anti-aggregation } \\
\text { protein }\end{array}$ & $\begin{array}{l}\text { Inhibition of hemocyte spreading and } \\
\text { aggregation, suppression of encapsulation }\end{array}$ & $\mathrm{Ph}$ & Richards and Dani (2008) \\
\hline RhOGAP & $\begin{array}{l}\text { Deformation of host hemocytes, suppression } \\
\text { of encapsulation }\end{array}$ & $\mathrm{Lb}$ & Labrosse et al. (2005) \\
\hline Similar to lethal (1) G0193 isoforms & & $\mathrm{Ci}$ & Vincent et al. (2010) \\
\hline Yellow-e3-like protein & & $\mathrm{Ci}$ & Vincent et al. (2010) \\
\hline
\end{tabular}


sion of the gene encoding extracellular SOD in the venom apparatus of the two species, the SOD protein being secreted in $L$. boulardi venom only (Colinet et al., 2011). This raises the question whether the venom of closely related species might essentially differ in the quantity of given proteins, leading to variation in virulence and/or host specificity.

\subsection{Venom differences between strains and populations}

Occurrence of intraspecific polymorphism in parasitoid virulence has rarely been documented. In L. boulardi, two well-defined strains were characterized, ISm, highly virulent only against $D$. melanogaster, and ISy, able to suppress immune defenses of both D. melanogaster and D. yakuba hosts, but depending on the host resistance genotype (Dubuffet et al., 2009). Physiological and biochemical approaches have demonstrated that these strains use different virulence strategies against Drosophila hosts, ISm inducing a permanent immunosuppression in $D$. melanogaster while suppression of $D$. yakuba encapsulation by ISy is transitory. Besides, ISm is known to target immune cellular components, resulting in changes in the morphology of $D$. melanogaster lamellocytes, whereas ISy targets the humoral component of encapsulation through inhibition of melanization. Remarkably, the venom composition of the strains differs extensively, as shown by protein electrophoretic profiles (Fig. 1).

Among the main venom factors identified in $L$. boulardi, some show no variation between strains (e.g. the extracellular SOD, qualitatively and quantitatively similar), while others display significant differences. The major virulence factor LbGAP for instance is secreted in a high amount in the venom of the ISm strain only (Fig. 1) (Colinet et al., 2010). Thanks to genetic analyses, it was

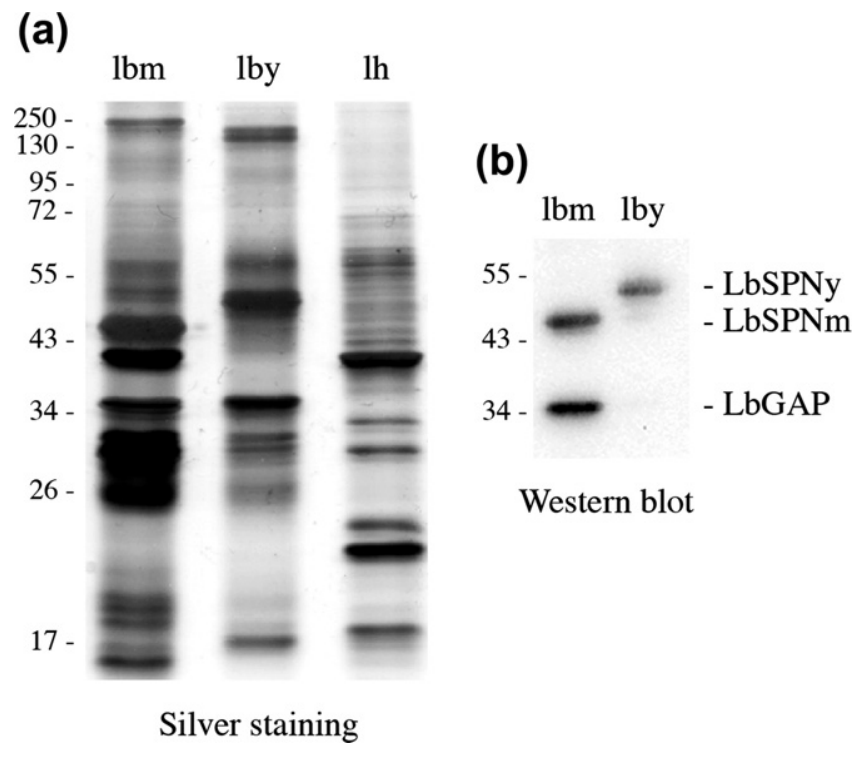

Fig. 1. Electrophoretic and immunoblot analyses of venom proteins in Leptopilina species. Venom reservoirs were dissected in insect Ringer solution supplemented with a protease inhibitors cocktail (PI; Roche) and residual tissues were removed by centrifugation. The total protein content of $10 \mathrm{~L}$. boulardi $\mathrm{ISm}(\mathrm{lbm}), 10 \mathrm{~L}$. boulardi ISy (lby) and $10 \mathrm{~L}$. heteretoma (lh) venom reservoirs was split in two, each part being run on a $10 \%$ SDS-PAGE under reducing conditions. One gel (a) was silver stained, the other (b) blotted onto nitrocellulose and used for immunodetection of LbGAP (rabbit polyclonal antibody; Labrosse et al., 2005) and LbSPN (rabbit polyclonal antibody raised against a synthetic peptide). Chemiluminescence signal detection was performed after incubation with a goat anti-rabbit IgG horseradish peroxidase conjugate. Positions of LbSPNy, LbSPNm and LbGAP venom proteins are indicated. Molecular weight standards in $\mathrm{kDa}$. shown that the quantitative variation between strains is likely due to differences in cis-regulation of transcription (Colinet et al., 2010). We have now indications that quantitative variation occurs for a number of venom proteins, suggesting that this mechanism may be largely involved in intraspecific variation of virulence (Colinet et al., preparation). Some preliminary data suggest that qualitative differences might also occur for some venom proteins: an antibody raised against a peptide from LbSPNy, identified from the ISy strain venom (Colinet et al., 2009), specifically recognizes an abundant protein in ISm venom that migrates at a lower position in the electrophoresis gel (Fig. 1). An open area of research is now to determine the respective contribution of quantitative and qualitative variation in the diversity of venom components and to decipher the molecular mechanisms responsible for this variation between strains and species.

\subsection{Venom differences between individuals}

It is intriguing and somehow frustrating that so little is known of the occurrence of venom components variability among individuals. We thus used a silver staining method with enough sensitivity to allow global analysis of venom electrophoretic patterns at the individual level, and tested this method on two species: the figitid L. boulardi, and the braconid Psyttalia lounsburyi. This last species, also raised in the laboratory, is used as a biological control agent against the devastating pest olive fly, Bactrocera oleae (Daane et al., 2011; Malausa et al., 2010). Since antibodies against $L$. boulardi virulence factors LbGAP and LbSPNy were available, we improved the method by using half of $L$. boulardi venom reservoir for individual electrophoretic analysis, and the other half to specifically detect and quantify proteins of interest on immunoblots (Fig. 2).

Electrophoretic profiles have been obtained for $L$. boulardi individuals from laboratory strains and from 8 natural populations sampled at different locations in the Rhône valley (France) (Fig. 2). Interestingly, all individuals from the Rhône valley had a L. boulardi ISm typical profile, with specific detection of LbGAP and LbSPNm (Fig. 2). To further investigate the inter-individual variability in venom proteins, reservoirs from $12 \mathrm{~L}$. boulardi females of a population sampled in St. Laurent d'Agny (Rhône valley, France) were individually separated by SDS-PAGE. Although the electrophoretic profiles were again roughly similar to the ISm profile for all individuals, clear differences were observed such as the presence or absence of specific bands (Fig. 3). Moreover, preliminary analyses on dot blots suggest occurrence of a quantitative variation of both LbGAP and LbSPNm between individuals, although this remains to be confirmed with more individuals, and precisely quantified. For $P$. lounsburyi, whose venom proteins have not yet been identified, the full content of the reservoir was analyzed on a gel. Venom protein profiles were obtained from 6 females recently collected in Sirimon Forest (Kenya) and 6 females from a strain also sampled in Kenya but maintained under laboratory conditions for more than 8 years ( $>100$ generations). They were roughly similar for all females, either recently collected or long-time reared in artificial conditions (Fig. 4). Interestingly, however, inter-individual variation was observed both qualitatively (presence/absence) and quantitatively (intensity of specific bands).

Interpretation of differences between individual electrophoretic profiles may encounter some difficulties. First, only one-dimensional electrophoresis can be performed with the quantity of material available in a single venom apparatus, and one band may contain different proteins. Besides, the presence/absence of a band may be due to strong quantitative differences, or to variation in the migration of a protein indicating the presence of different alleles or of post-translational modifications. However, all these modifica- 
(a)

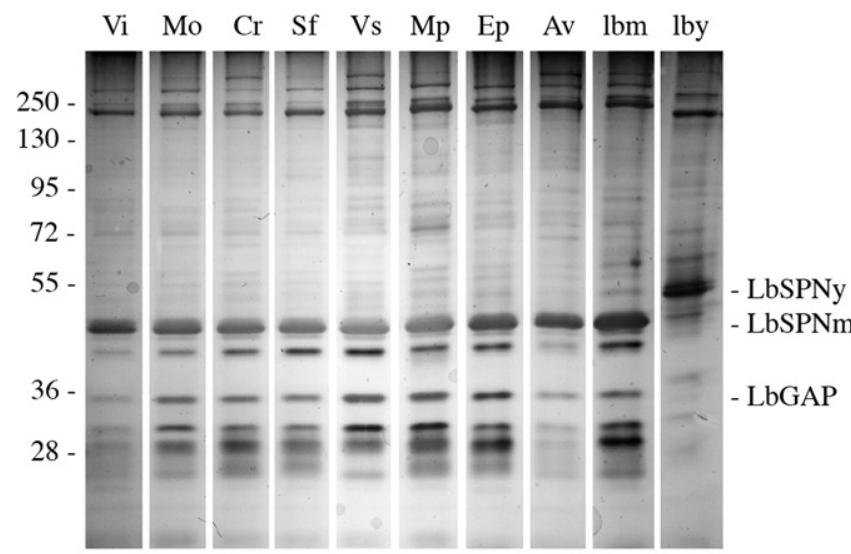

SDS-PAGE $12.5 \%$

(b)

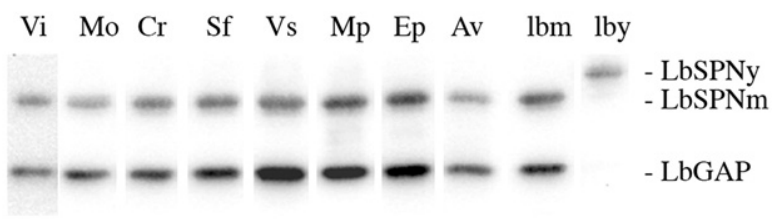

Western blot

Fig. 2. Electrophoretic and immunoblot analyses of venom contents from Leptopilina boulardi individuals of natural populations. Individual protein contents of $8 \mathrm{~L}$. boulardi venom reservoirs (collected as in Fig. 1) were split and migrated on two $10 \%$ SDS-PAGE under reducing conditions. The two gels were treated as in Fig. 1. $L$ boulardi individuals were samples from 8 populations along a $300 \mathrm{~km} \mathrm{~N}-\mathrm{S}$ gradient in the Rhône valley (France): Villette-de-Vienne (Vi), Mollèges (Mo), La Crau ( $\mathrm{Cr}$ ), Sainte-Foy-lès-Lyon (Sf), Ville-Sollier (Vs), Montpellier (Mp), Epinouze (Ep) and Avignon (Av). Controls are aliquots (equivalent to one individual) from a pool of either $10 \mathrm{~L}$. boulardi ISm (lbm) or $10 \mathrm{~L}$. boulardi ISy (lby) venom reservoirs. Positions of LbSPNy, LbSPNm and LbGAP venom proteins and molecular weight standards (in $\mathrm{kDa})$ are indicated.

tions might be correlated with changes in parasitoid virulence and are worth to be taken into consideration.

Altogether, these preliminary data demonstrate the occurrence of parasitoid venom variability at the individual level, both in field populations and laboratory strains, in different phylogenetic groups. The consistent variability observed in parasitoid venom, even with a low number of tested individuals, suggest a large potential for rapid adaptation of parasitoids to changes in host physiology or host species.

\section{Conclusion}

Thanks to new impressive technological steps, our knowledge of parasitoid venom proteins will rapidly increase. cDNA can now be extracted and sequenced from nanogram amounts by next generation sequencing (Head et al., 2011), and less than picograms amount of peptides can be identified by mass spectrometry (Bantscheff et al., 2008). The sequencing of endoparasitoid genomes will allow wide population analyses of venom transcripts and proteins, thus leading to accurate estimations of individual variation. Parasitoid wasps however represent a large and diverse group and simplest approaches, such as individual electrophoretic comparisons, may remain of interest for species without genome sequence support. Regarding genetic approaches, RNA interference techniques have proved efficient in an ectoparasitoid wasp (Lynch and Desplan, 2006; Werren et al., 2009), and their development for endoparasitoids will be crucial. By helping determining if a given protein plays a role in parasitoid virulence, it will both allow to (a)

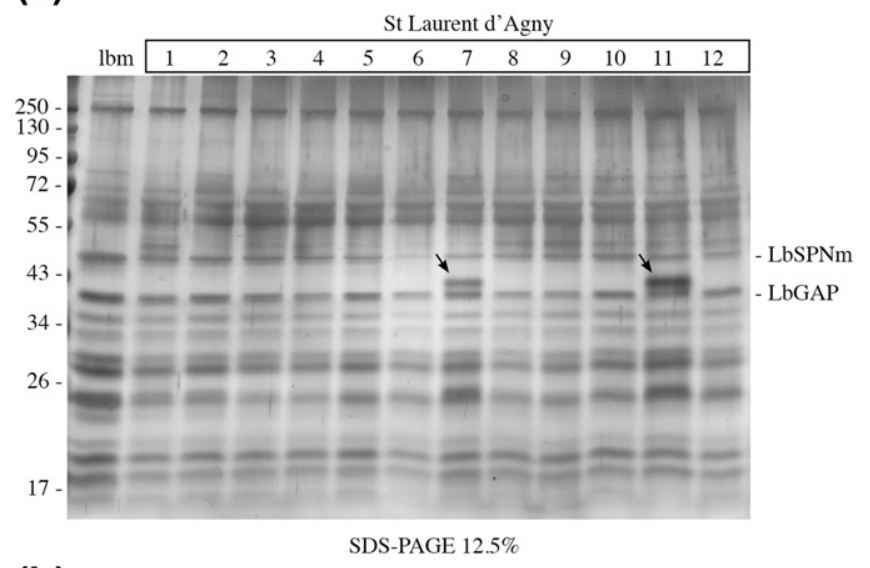

(b)

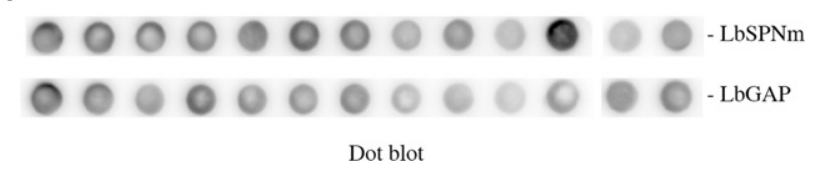

Fig. 3. Electrophoretic and dot blot analyses of venom proteins from Leptopilina boulardi individuals from one field population. The individual protein contents of 12 L. boulardi individual venom reservoirs were treated as in Fig. 2 . Individuals belong from a population of St. Laurent d'Agny (Rhône valley, near Lyon, France). Controls are as in Fig. 2. The arrows point to a specific band present in the venom of two females, as an example of the observed inter-individual variation. Positions of LbSPNm and LbGAP and molecular weight standards (in $\mathrm{kDa}$ ) are indicated.

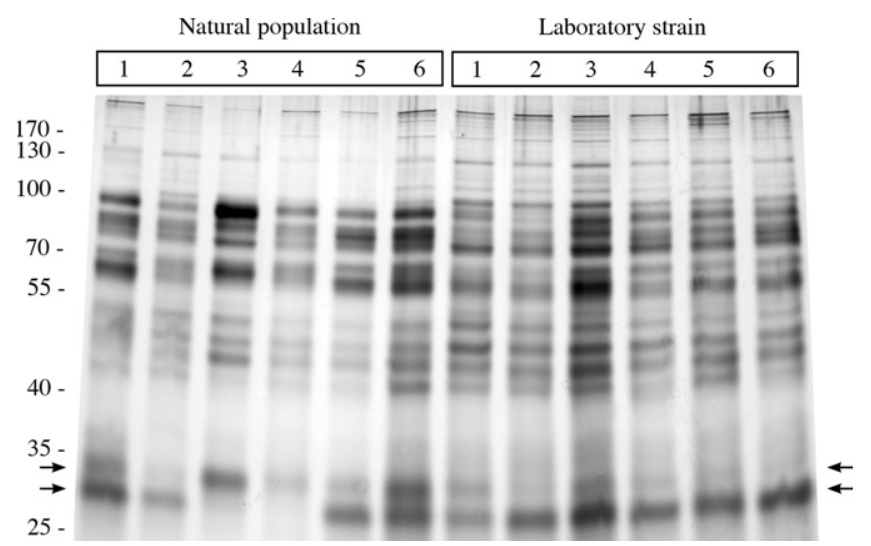

Fig. 4. Electrophoretic comparison of venom proteins from Psyttalia lounsbury individuals. The individual protein contents of 12 individual venom glands (prepared as in Fig. 1), was analyzed under reducing conditions on a 12.5\% SDSPAGE and visualized by silver staining. 6 individuals originate from a population sampled in Sirimon Forest (Kenya), the other 6 being issued from a strain collected in Kenya but reared in laboratory conditions for more than 8 years. Arrows point to examples of inter-individual variation with the presence/absence of bands in the natural population or quantitative variation of specific bands in the laboratory strain. Molecular weight standards are in $\mathrm{kDa}$.

focus studies on essential proteins, and to obtain venom protein markers under selection for population approaches.

\section{Acknowledgements}

We are grateful to Christian Rebuf and Marcel Thaon for help in insect rearing, Pierre Girod and Fanny Cavigliasso for technical assistance, the French National Institute for Agricultural Research (INRA) units of Avignon and Gotheron and the land owners for allowing insect collection in their orchards, Julien Martinez for sending $L$. boulardi samples from the Rhône valley (France), and 
the ICIPE fruit fly project staff for sampling P. lounsburyi in Kenya. We also thank Thibaut Malausa and Nicolas Ris for fruitful discussions. This work was funded by the CLIMEVOL (ANR-08-BLAN0231) Project from the French National Research Agency, and grants from the INRA Department of Plant Health and Environment (SPE). H. Mathé-Hubert is supported by a Ph.D. funding from the Provence Alpes Côte d'Azur (PACA) region and INRA.

\section{References}

Asgari, S., 2012. Venoms from endoparasitoids. In: Beckage, N.E., Drezen, J.-M. (Eds.), Parasitoid Viruses: Symbionts and Pathogens. Academic Press, London, pp. 215-231.

Asgari, S., Rivers, D.B., 2010. Venom proteins from endoparasitoid wasps and their role in host-parasite interactions. Annual Review of Entomology 56, 313-335.

Asgari, S., Zhang, G., Zareie, R., Schmidt, O., 2003a. A serine proteinase homolog venom protein from an endoparasitoid wasp inhibits melanization of the host hemolymph. Insect Biochemistry and Molecular Biology 33, 1017-1024.

Asgari, S., Zareie, R., Zhang, G., Schmidt, O., 2003b. Isolation and characterization of a novel venom protein from an endoparasitoid, Cotesia rubecula (Hym: Braconidae). Archives of Insect Biochemistry and Physiology 53, 92-100.

Bantscheff, M., Boesche, M., Eberhard, D., Matthieson, T., Sweetman, G., Kuster, B., 2008. Robust and sensitive iTRAQ quantification on an LTQ orbitrap mass spectrometer. Molecular \& Cellular Proteomics 7 (9), 1702-1713.

Beckage, N.E., 2012. Polydnaviruses as endocrine regulators. In: Beckage, N.E., Drezen, J.-M. (Eds.), Parasitoid Viruses: Symbionts and Pathogens. Academic Press, London, pp. 163-168.

Belleannée, C., Labas, V., Teixeira-Gomes, A.P., Gatti, J.-L., Dacheux, J.-L., Dacheux, F., 2010. Identification of luminal and secreted proteins in bull epididymis. Journal of Proteomics 74, 59-78.

Burke, G.R., Strand, M.R., 2012. Polydnaviruses of parasitic wasps: domestication of viruses to act as gene delivery vectors. Insects 3, 91-119.

Carton, Y., Poirié, M., Nappi, A.J., 2008. Insect immune resistance to parasitoids. Insect Science 15, 67-87.

Chapman, T., 2008. The soup in my fly: evolution, form and function of seminal fluid proteins. PLoS Biology 6, e179.

Chiu, H., Morales, J., Govind, S., 2006. Identification and immuno-electron microscopy localization of $\mathrm{p} 40$, a protein component of immunosuppressive virus-like particles from Leptopilina heterotoma, a virulent parasitoid wasp of Drosophila. Journal of General Virology 87, 461-470.

Colinet, D., Schmitz, A., Depoix, D., Crochard, D., Poirié, M., 2007. Convergent use of RhoGAP toxins by eukaryotic parasites and bacterial pathogens. PLoS Pathogens 3, e203.

Colinet, D., Dubuffet, A., Cazes, D., Moreau, S., Drezen, J.-M., Poirié, M., 2009. A serpin from the parasitoid wasp Leptopilina boulardi targets the Drosophila phenoloxidase cascade. Developmental and Comparative Immunology 33, 681-689.

Colinet, D., Schmitz, A., Cazes, D., Gatti, J.-L., Poirié, M., 2010. The origin of intraspecific variation of virulence in an eukaryotic immune suppressive parasite. PLoS Pathogens 6, e1001206.

Colinet, D., Cazes, D., Belghazi, M., Gatti, J.-L., Poirié, M., 2011. Extracellular superoxide dismutase in insects: characterization, function, and interspecific variation in parasitoid wasp venom. Journal of Biological Chemistry 286, 40110-40121.

Colinet D., Deleury E., Anselme C., Cazes D., Poulain J., Belghazi M., Gatti J.-L., Poirié M., Closely related parasites targeting the same host can show extensive venom variation: the case of Leptopilina parasitoids of Drosophila in preparation.

Crawford, A.M., Brauning, R., Smolenski, G., Ferguson, C., Barton, D., Wheeler, T.T., McCulloch, A., 2008. The constituents of Microctonus sp. parasitoid venoms. Insect Molecular Biology 17, 313-324.

Daane, M.K., Johnson, M.W., Pickett, C.H., Sime, K.R., Wang, X.-G., Nadel, H., Andrews Jr., J.W., Hoelmer, K.A., 2011. Biological controls investigated to aid management of olive fruit fly in California. California Agriculture 65, 21-28.

Dani, M.P., Edwards, J.P., Richards, E.H., 2005. Hydrolase activity in the venom of the pupal endoparasitic wasp, Pimpla hypochondriaca. Comparative Biochemistry and Physiology B 141, 373-381.

Danneels, E.L., Rivers, D.B., de Graaf, D.C., 2010. Venom proteins of the parasitoid wasp Nasonia vitripennis: recent discovery of an untapped pharmacopee. Toxins 2, 494-516.

de Graaf, D.C., Aerts, M., Brunain, M., Desjardins, C.A., Jacobs, F.J., Werren, J.H., Devreese, B., 2010. Insights into the venom composition of the ectoparasitoid wasp Nasonia vitripennis from bioinformatic and proteomic studies. Insect Molecular Biology 19, 11-26.

Dubuffet, A., Colinet, D., Anselme, C., Dupas, S., Carton, Y., Poirié, M., 2009. Variation of Leptopilina boulardi success in Drosophila hosts: what is inside the black box? Advances in Parasitology 70, 147-188.

Dupas, S., Brehelin, M., Frey, F., Carton, Y., 1996. Immune suppressive virus-like particles in a Drosophila parasitoid: significance of their intraspecific morphological variations. Parasitology 113, 207-212.

Dupas, S., Dubuffet, A., Carton, Y., Poirié, M., 2009. Local, geographic and phylogenetic scales of coevolution in Drosophila-parasitoid interactions. Advances in Parasitology 70, 281-295.
Edson, K.M., Vinson, S.B., 1979. A comparative morphology of the venom apparatus of female braconids (Hymenoptera: Braconidae). Canadian Entomologist 111, 1013-1024.

Edson, K.M., Barlin, M.R., Vinson, S.B., 1982. Venom apparatus of braconid wasps: comparative ultrastructure of reservoirs and gland filaments. Toxicon 20, 553562.

Falabella, P., Riviello, L., Caccialupi, P., Rossodivita, T., Teresa Valente, M., Luisa De Stradis, M., Tranfaglia, A., Varricchio, P., Gigliotti, S., Graziani, F., Malva, C., Pennacchio, F., 2007. A gamma-glutamyl transpeptidase of Aphidius ervi venom induces apoptosis in the ovaries of host aphids. Insect Biochemistry and Molecular Biology 37, 453-465.

Fauvarque, M.O., Williams, M.J., 2011. Drosophila cellular immunity: a story of migration and adhesion. Journal of Cell Science 124, 1373-1382.

Fleury, F., Gibert, P., Ris, N., Allemand, R., 2009. Ecology and life history evolution of frugivorous drosophila parasitoids. Advances in Parasitology 70, 3-44.

Formesyn, E.M., Danneels, E.L., de Graaf, D.C., 2012. Proteomics of the venom of the parasitoid Nasonia vitripennis. In: Beckage, N.E., Drezen, J.-M. (Eds.), Parasitoid Viruses: Symbionts and Pathogens. Academic Press, London, pp. 233-246.

Fry, B.G., Roelants, K., Champagne, D.E., Scheib, H., Tyndall, J.D.A., King, G.F., Nevalainen, T.J., Norman, J.A., Lewis, R.J., Norton, R.S., Renjifo, C., de la Vega, R.C.R., 2009. The toxicogenomic multiverse: convergent recruitment of proteins into animal venoms. Annual Review of Genomics and Human Genetics 10, 483511.

Gatti, J.-L., Schmitz, A., Colinet, D., Poirié, M., 2012. Diversity of virus-like particles in parasitoids' venom: viral or cellular origin? In: Beckage, N.E., Drezen, J.-M. (Eds.), Parasitoid Viruses: Symbionts and Pathogens. Academic Press, London, pp. 181-192.

Godfray, H.C.J., 1994. Parasitoids: Behavioural and Evolutionary Ecology. Princeton University Press, Princeton.

Hanash, S., Taguchi, A., 2010. The grand challenge to decipher the cancer proteome. Nature Reviews Cancer 10, 652-660.

Hauser, F., Neupert, S., Williamson, M., Predel, R., Tanaka, Y., Grimmelikhuizen, C.J., 2010. Genomics and peptidomics of neuropeptides and protein hormones present in the parasitic wasp Nasonia vitripennis. Journal of Proteome Research 9, 5296-5310.

Head, S.R., Komori, H.K., Hart, G.T., Shimashita, J., Schaffer, L., Salomon, D.R., Ordoukhanian, P.T., 2011. Method for improved Illumina sequencing library preparation using NuGEN ovation RNA-Seq system, 2011. BioTechniques 50, $177-180$.

Jenni, W., 1951. Beitrag zur morphologie und biologie der cynipide Pseudocoila bochei Weld, eines larvenparasiten von Drosophila melanogaster Meig. Acta Zoologica 32, 177-254

Jervis, M.A., Ellers, J., Harvey, J.A., 2008. Resource acquisition, allocation, and utilization in parasitoid reproductive strategies. Annual Review of Entomology 53, 361-385.

Kraaijeveld, A.R., van Alphen, J., 1994. Geographical variation in resistance of the parasitoid Asobara tabida against encapsulation by Drosophila melanogaster larvae: the mechanisms explored. Physiological Entomology 19, 9-14.

Krishnan, A. Nair, P.N. Jones, D. 1994. Isolation, cloning, and characterization of new chitinase stored in active form in chitin-lined venom reservoir. Journal of Biological Chemistry 33, 20971-20976.

Labrosse, C., Stasiak, K., Lesobre, J., Grangeia, A., Huguet, E., Drezen, J.-M., Poirié, M., 2005. A RhoGAP protein as a main immune suppressive factor in the Leptopilina boulardi (Hymenoptera, Figitidae)-Drosophila melanogaster interaction. Insect Biochemistry and Molecular Biology 35, 93-103.

Lee, M.J., Kalamarz, M.E., Paddibhatla, I., Small, C., Rajwani, R., Govind, S., 2009. Virulence factors and strategies of Leptopilina spp.: selective responses in Drosophila hosts. Advances in Parasitology 70, 123-145.

Lee, M.J., Mondal, A., Small, C., Paddibhatla, I., Kawaguchi, A., Govind, S., 2011. A database for the analysis of immunity genes in Drosophila: PADMA database. Fly $5,155-161$

Leluk, J., Schmidt, J., Jones, D., 1989. Comparative studies on the protein composition of hymenopteran venom reservoirs. Toxicon 27, 105-114.

Lohse, K., Barton, N.H., Melika, G., Stone, G.N., 2012. A likelihood-based comparison of population histories in a parasitoid guild. Molecular Ecology 21 (18), 46054617.

Lynch, J.A., Desplan, C., 2006. A method for parental RNA interference in the wasp Nasonia vitripennis. Nature Protocols 1, 486-494.

Mabiala-Moundoungou, A., Doury, G., Eslin, P., Cherqui, A., Prévost, G., 2010. Deadly venom of Asobara japonica parasitoid needs ovarian antidote to regulate host physiology. Journal of Insect Physiology 56, 35-41.

Malausa, J.-C., Auguste-Maros, A., Cheyppe-Buchmann, S., Groussier-Bout, G., Ris, N., Thaon, M., Warot, S., Fauvergue, X., 2010. Introductions of the African parasitoid Psyttalia lounsburyi in South of France for classical biological control of Bactrocera oleae. IOBC/wprs Bulletin 59, 163-170.

Morales, J., Chiu, H., Oo, T., Plaza, R., Hoskins, S., Govind, S., 2005. Biogenesis, structure, and immune-suppressive effects of virus-like particles of a Drosophila parasitoid, Leptopilina victoriae. Journal of Insect Physiology 51, 181-195.

Moreau, S.J.M., Cherqui, A., Doury, G., Dubois, F., Fourdrain, Y., Sabatier, L., Bulet, P., Saarela, J., Prevost, G., Giordanengo, P., 2004. Identification of an aspartylglucosaminidase-like protein in the venom of the parasitic wasp Asobara tabida (Hymenoptera: Braconidae). Insect Biochemistry and Molecular Biology 34, 485-492.

Nakamatsu, Y., Tanaka, T., 2004. Venom of Euplectrus separatae causes hyperlipidemia by lysis of host fat body cells. Journal of Insect Physiology 50, 267-275. 
Nappi, A.J., 1977. Factors affecting the ability of the wasp parasite Pseudeucoila bochei to inhibit tumourigenesis in Drosophila melanogaster. Journal of Insect Physiology 23, 809-812.

Nappi, A.J., 2010. Cellular immunity and pathogen strategies in combative interactions involving Drosophila hosts and their endoparasitic wasps. Invertebrate Survival Journal 7, 198-210.

Nappi, A.J., Poirié, M., Carton, Y., 2009. The role of melanization and cytotoxic byproducts in the cellular immune response of Drosophila against parasitic wasps. Advances in Parasitology 70, 100-121.

Parkinson, N., Smith, I., Weaver, R., Edwards, J.P., 2001. A new form of arthropod phenoloxidase is abundant in venom of the parasitoid wasp Pimpla hypochondriaca. Insect Biochemistry and Molecular Biology 31, 57-63.

Parkinson, N., Conyers, C., Smith, I., 2002a. A venom protein from the endoparasitoid wasp Pimpla hypochondriaca is similar to snake venom reprolysin-type metalloproteases. Journal of Invertebrate Pathology 79, 129-131.

Parkinson, N., Richards, E.H., Conyers, C., Smith, I., Edwards, J.P., 2002b. Analysis of venom constituents from the parasitoid wasp Pimpla hypochondriaca and cloning of a cDNA encoding a venom protein. Insect Biochemistry and Molecular Biology 32, 729-735.

Parkinson, N., Smith, I., Audsley, N., Edwards, J.P., 2002c. Purification of pimplin, a paralytic heterodimeric polypeptide from venom of the parasitoid wasp Pimpla hypochondriaca, and cloning of the cDNA encoding one of the subunits. Insect Biochemistry and Molecular Biology 32, 1769-1773.

Parkinson, N.M., Conyers, C.M., Keen, J.N., MacNicoll, A.D., Smith, I., Weaver, R.J., 2003. CDNAs encoding large venom proteins from the parasitoid wasp Pimpla hypochondriaca identified by random sequence analysis. Comparative Biochemistry and Physiology 134, 513-520.

Parkinson, N.M., Conyers, C., Keen, J., MacNicoll, A., Smith, I., Audsley, N., Weaver, R., 2004. Towards a comprehensive view of the primary structure of venom proteins from the parasitoid wasp Pimpla hypochondriaca. Insect Biochemistry and Molecular Biology 34, 565-571.

Pilch, B., Mann, M., 2006. Large-scale and high-confidence proteomic analysis of human seminal plasma. Genome Biology 7, R40.

Poirié, M., Carton, Y., Dubuffet, A., 2009. Virulence strategies in parasitoid hymenoptera as an example of adaptive diversity. Comptes Rendus de l'Académie des Sciences 332, 311-320.

Price, D., Bell, H., Hinchliffe, G., Fitches, E., Weaver, R., Gatehouse, J., 2009. A venom metalloproteinase from the parasitic wasp Eulophus pennicornis is toxic towards its host, tomato moth (Lacanobia oleracae). Insect Molecular Biology 18, 195-202.

Quicke, D.L.J., 1997. Parasitic Wasps. Chapman \& Hall, London.

Richards, E.H., Dani, M.P., 2008. Biochemical isolation of an insect haemocyte antiaggregation protein from the venom of the endoparasitic wasp, Pimpla hypochondriaca, and identification of its gene. Journal of Insect Physiology 54 1041-1049.

Rizki, R.M., Rizki, T.M., 1984. Selective destruction of a host blood cell type by a parasitoid wasp. Proceedings of the National Academy of Sciences United States of America 81, 6154-6158.

Rizki, R.M., Rizki, T.M., 1990. Parasitoid virus-like particles destroy Drosophila cellular immunity. Proceedings of the National Academy of Sciences United States of America 87, 8388-8392.

Rizki, T.M., Rizki, R.M., 1994. Parasitoid-induced cellular immune deficiency in Drosophila. Annals of the New York Academy of Sciences 712, 178-194.

Rizki, T.M., Rizki, R.M., Carton, Y., 1990. Leptopilina heterotoma and L. boulardi: strategies to avoid cellular defense responses of Drosophila melanogaster. Experimental Parasitology 70, 466-475.
Schlenke, T.A., Morales, J., Govind, S., Clark, A.G., 2007. Contrasting infection strategies in generalist and specialist wasp parasitoids of Drosophila melanogaster. PLoS Pathogens 3, 1486-1501.

Strand, M., 2008. Insect hemocytes and their role in immunity. In: Beckage, N.E. (Ed.), Insect Immunity. Academic Press, San Diego, CA, pp. 248-256.

Strand, M.R., 2012. Polydnavirus gene products that interact with the host immune system. In: Beckage, N.E., Drezen, J.-M. (Eds.), Parasitoid Viruses: Symbionts and Pathogens. Academic Press, London, pp. 149-161.

Suzuki, M., Miura, K., Tanaka, T., 2008. The virus-like particles of a Braconid endoparasitoid wasp, Meteorus pulchricornis, inhibit hemocyte spreading in its noctuid host, Pseudaletia separata. Journal of Insect Physiology 54, 10151022.

Tian, C., Wang, L., Ye, G., Zhu, S., 2010. Inhibition of melanization by a Nasonia defensin-like peptide: implications for host immune suppression. Journal of Insect Physiology 56, 1857-1862.

Uçkan, F., Ergin, E., Rivers, D.B., Gençer, N., 2006. Age and diet influence the composition of venom from the endoparasitic wasp Pimpla turionellae L. (Hymenoptera: Ichneumonidae). Archives of Insect Biochemistry and Physiology 63, 177-187.

Vardal, H., 2006. Venom gland and reservoir morphology in cynipoid wasps. Arthropod Structure and Development 35, 127-136.

Vincent, B., Kaeslin, M., Roth, T., Heller, M., Poulain, J., Cousserans, F., Schaller, J., Poirié, M., Lanzrein, B., Drezen, J.-M., Moreau, S.J.M., 2010. The venom composition of the parasitic wasp Chelonus inanitus resolved by combined expressed sequence tags analysis and proteomic approach. BMC Genomics 11, 693.

Wajnberg, E., Coquillard, P., Vet, L.E.M., Hoffmeister, T., 2012. Optimal resource allocation to survival and reproduction in parasitic wasps foraging in fragmented habitats. PLoS One 7, e38227.

Werren, J.H., Loehlin, D.W., Giebel, J.D., 2009. Larval RNAi in Nasonia (parasitoid wasp). CSH Protocols, pdb.prot5311.

Wulfkuhle, J.D., Liotta, L.A., Petricoin, E.F., 2003. Proteomic applications for the early detection of cancer. Nature Reviews Cancer 3, 267-275.

Zhang, G., Schmidt, O., Asgari, S., 2004a. A novel venom peptide from an endoparasitoid wasp is required for expression of polydnavirus genes in host hemocytes. Journal of Biological Chemistry 279, 41580-41585.

Zhang, G., Lu, Z.-Q., Jiang, H., Asgari, S., 2004b. Negative regulation of prophenoloxidase (proPO) activation by a clip-domain serine proteinase homolog (SPH) from endoparasitoid venom. Insect Biochemistry and Molecular Biology 34, 477-483.

Zhang, G., Schmidt, O., Asgari, S., 2006. A calreticulin-like protein from endoparasitoid venom fluid is involved in host hemocyte inactivation. Developmental and Comparative Immunology 30, 756-764.

Zhou, L., Lu, Z., Yang, A., Deng, R., Mai, C., Sang, X., Faber, N.F., Lu, X.H., 2007. Comparative proteomic analysis of human pancreatic juice. Methodological study. Proteomics 7 (8), 1345-1355.

Zhu, J., Ye, G., Hu, C., 2008. Molecular cloning and characterization of acid phosphatase in venom of the endoparasitoid wasp Pteromalus puparum (Hymenoptera: Pteromalidae). Toxicon 51, 1391-1399.

Zhu, J.-Y., Ye, G.Y., Fang, Q., Hu, C., 2010a. Alkaline phosphatase from venom of the endoparasitoid wasp, Pteromalus puparum. Journal of Insect Science 10, 1 15.

Zhu, J.-Y., Fang, Q., Wang, L., Hu, C., Ye, G.Y., 2010b. Proteomic analysis of the venom from the endoparasitoid wasp Pteromalus puparum (Hymenoptera: Pteromalidae). Archives of Insect Biochemistry and Physiology 75, 28-44. 